\title{
AYUDA MULTILATERAL EFICIENTE ENTRE PAÍSES Y ORGANIZACIONES INTERNACIONALES CONTRA INCENDIOS FORESTALES: Condiciones técnicas básicas
}

\author{
Ricardo Vélez ${ }^{1}$
}

\section{RESUMEN}

La globalización da lugar a operaciones de ayuda multilateral entre países contra incendios forestales. Se enumeran los tipos de asistencia y se detalla el contenido de los Acuerdos de cooperación internacional. Como ejemplo, se presenta el Plan de ayuda mutua entre España y Portugal.

\section{INTRODUCCIÓN}

La globalización ha llegado también a los incendios forestales.

La teledetección permite conocer en plazos muy breves la presencia de grandes incendios en cualquier parte del mundo, medir la superficie afectada, cuando se extinguen, y evaluar sus efectos ambientales a larga distancia.

La información, en éste como en otros fenómenos que pueden afectar al ambiente, está creando una nueva conciencia: Un incendio forestal no es sólo un suceso local, sino además un elemento de un conjunto global que puede contribuir a modificar las condiciones de vida en el planeta Tierra.

Esta nueva conciencia produce movimientos de cooperación para controlar también globalmente los efectos del fuego, trasladando recursos de unos países a otros o contribuyendo a fortalecer la capacidad local de control de los incendios.

En los pasados años se han producido operaciones de traslado de recursos a larga distancia. Se pueden mencionar dentro del presente siglo XXI:

- Años 2000 y 2002: Medios de Australia, Nueva Zelanda, México y Canadá a Estados Unidos.

- Años 2002 y 2003: Medios de Estados Unidos y Nueva Zelanda a Australia.

- Año 2003: Medios de España a Portugal durante 19 días y a Francia durante 5 días.

Al final del siglo XX se produjeron otras operaciones internacionales frente a los incendios en Indonesia y en Rondonia (Brasil), etc.

En octubre de 2003, al final de la III Conferencia Internacional sobre Incendios Forestales, Sydney, se celebró una Cumbre en la que se identificaron una serie de principios y de instrumentos técnicos para promover y fortalecer la cooperación global para el control de los incendios forestales.

\section{Tipos de cooperación y ayuda}

La cooperación entre países puede presentar formas muy variadas.

Ayuda mutua

Consiste en la ayuda para controlar incendios generalmente en zonas fronterizas, aunque se pueda ampliar a otras zonas e incluso plantearse entre países no fronterizos.

Generalmente se acuerda que esta ayuda se presta sin repercutir costes, ya que las partes del acuerdo se pueden beneficiar del mismo en cualquier momento.

Ayuda cooperativa

Es una ampliación de la anterior con apoyo de expertos para el desarrollo de acciones de protección en el país que recibe la ayuda.

Los costes pueden ser no reembolsables o compartidos.

Intercambio técnico

\footnotetext{
${ }^{1}$ Jefe del Área de Defensa contra Incendios Forestales, Ministerio de Medio Ambiente, DGB, Gran Vía San Francisco 4, 28005 Madrid, rvelez@mma.es
} 
Se trata de actividades que generalmente no precisan la firma de acuerdos. Consisten en la transferencia de información de unos técnicos a otros y no incluyen la intervención de recursos de extinción. Normalmente cada parte cubre sus propios costes.

Asistencia técnica

Consiste en el envío de expertos de un país a otro para mejorar o fortalecer la capacidad del país que recibe la asistencia en determinados aspectos de la defensa contra incendios forestales. El objetivo será reducir la necesidad de futura ayuda en el futuro. Normalmente es costeada por el país que ofrece la asistencia.

Ayuda en desastres

Se trata de una ayuda por razones humanitarias, ecológicas, sanitarias o económicas para hacer frente a las consecuencias de desastres. Se presta inmediatamente después del evento y durante un periodo limitado, hasta que el país afectado consigue controlar la situación. acuerdos.

Es siempre no reembolsable y se presta dentro de acuerdos bilaterales o es la causa de futuros

\section{Esquema de un Acuerdo de cooperación internacional}

Partes del Acuerdo

- $\quad$ Organismos gubernamentales o no gubernamentales

Objetivo del Acuerdo

- $\quad$ Define campos y formas de cooperación

- $\quad$ Define la finalidad de la cooperación

\section{Definiciones}

- Se definen los conceptos de la cooperación para evitar confusiones o interpretaciones erróneas del contenido del Acuerdo

Costes

- $\quad$ Personal y equipo: Se definen los costes incluidos en el Acuerdo

- Reembolso de los costes: Establece el procedimiento de reembolso y los costes que se reembolsarán. Algunos acuerdos prevén que el país receptor de la ayuda cubra los costes a partir de cierta cantidad o que la ayuda sea no reembolsable.

Información y coordinación

- Canales de comunicación: Define los protocolos y métodos para intercambiar información

- Intercambio de información: Define el tipo de información que se transmitirá y los tiempos del intercambio

- $\quad$ Notificaciones: Define los procedimientos para informar de las emergencias y solicitar ayuda

- Coordinación en la emergencia: Define la estructura organizativa en la que se integrarán los medios de ayuda

Responsabilidades

- Define las responsabilidades mutuas en que pueden incurrir los medios de ayuda y los receptores de la misma y las exenciones a las mismas

- $\quad$ Define también las responsabilidades frente a terceros

- $\quad$ Asistencia médica: Define como se cubrirá, así como la evacuación eventual de personal

- $\quad$ Compensaciones en caso de accidente o muerte

- $\quad$ Privilegios e inmunidades para el personal que presta la ayuda: Define el nivel de inmunidad de que gozará el personal que presta la ayuda, con el objetivo de facilitar su trabajo

Planes de operaciones 
Son parte esencial del Acuerdo para hacerlo efectivo y eficiente. Incluye conceptos tales como puntos de contacto, forma de solicitar la ayuda, procedimientos de entrada en el otro país, actualizaciones de los costes, reembolsos, normas técnicas relativas a personal, equipo, ejercicios de precampaña, cartografía, intercambio de informes, frecuencia de las revisiones del plan, logística, etc.

Paso de fronteras

- $\quad$ Protocolos para simplificar el paso de fronteras para el personal, el equipo y los materiales y las aeronaves

Enlace con el Plan de Manejo de Desastres

- Explica como se integrará el plan de ayuda en el más amplio Plan de Manejo de Desastres, elaborado por el país que recibe la ayuda.

Temas generales

- $\quad$ Periodo de vigencia del Acuerdo (fechas concretas)

- Duración

- $\quad$ Procedimiento para denuncia del Acuerdo

- Terminación: Circunstancias para la cancelación del Acuerdo

- Interpretación: Explicaciones sobre conceptos que pueden generar dudas

- $\quad$ Resolución de disputas: Métodos para resolverlas

- $\quad$ Enmiendas: Procedimientos para introducir modificaciones al Acuerdo

Normas sobre procedimientos operativos

- Describe procedimientos tales como la organización de las operaciones de extinción, sistemas de comunicaciones, seguridad del personal, apoyo logístico del país que recibe la ayuda, etc.

- $\quad$ Ejercicios y simulaciones para preparar las operaciones a escala real

Otros temas

Las partes pueden estar interesadas en definir temas relativos a:

- $\quad$ Formación de personas

- Intercambios técnicos

- $\quad$ Normas sobre personal

- $\quad$ Equipo de seguridad personal

- $\quad$ Limitaciones para el uso de algunos equipos

- $\quad$ Retirada de recursos

Firmas de las partes

\section{Eficiencia de la cooperación}

Personal

La cooperación consiste esencialmente en trabajo conjunto entre personas, por ello es fundamental que el personal, que se envía para prestar la ayuda, sea seleccionado adecuadamente para que los resultados sean los esperados.

Algunos puntos que se pueden señalar a este respecto son los siguientes:

- Idioma: El personal cooperante debe poder comunicarse con el personal que recibe la ayuda. Si no fuera posible hacerlo directamente, se necesitarán intérpretes

- Sensibilidad cultural: El respeto mutuo por las diferencias culturales será imprescindible (leyes, vestido, comida, religión, etc)

- Competencia técnica: El personal que presta la ayuda debe ser el que efectivamente puede desempeñar las funciones que componen dicha ayuda. Es decir, el personal, que se envía, será seleccionado por sus conocimientos concretos y no por su rango en la organización que presta la ayuda.

Bases de datos y predicción del peligro 
La preparación de la ayuda requiere disponer de una base de datos que facilite la determinación de las zonas y épocas de peligro, frecuencia de incendios, causas de los mismos, etc. Asimismo es necesario que exista una metodología para predecir el peligro y que se intercambien mapas de su evolución para anticipar la disponibilidad de recursos.

\section{Ejemplo de protocolo de cooperación: El Plan de mutua ayuda fronteriza entre España y Portugal}

La cooperación contra incendios forestales entre España y Portugal se basa en un Acuerdo General de Ayuda Mutua en Emergencias de Protección Civil firmado entre ambos países en 1962.

Debido a los frecuentes incendios en zona fronteriza, generalmente iniciados en Portugal e impulsados por el viento Oeste hacia España, en el año 2003 se preparó un Protocolo complementario para descentralizar la movilización de medios para el ataque a estos fuegos.

Los grandes incendios de julio y agosto en Portugal pusieron de manifiesto la necesidad de dicha descentralización, concluyendo en noviembre de dicho año la preparación y firma del Protocolo. Se transcribe a continuación, de modo esquemático, el funcionamiento del mismo:

\section{Ayuda mutua contra incendios forestales en la zona fronteriza entre España y Portugal}

Protocolo operativo. 8 noviembre 2003

Zona fronteriza:

Faja de $5 \mathrm{~km}$ a ambos lados de la frontera entre los dos países.

Autoridades competentes:

\section{Caso 1:}

Portugal: $\quad$ Gobernador Civil del Distrito

España: $\quad$ El Subdelegado del Gobierno en la provincia

Incendio en el país $A$, detectado en zona fronteriza por el país $B$, con alta probabilidad de que pase a $B$ :

- En España: Detectado por la C.A.

- La autoridad en España informa a la Autoridad en Portugal y envía medios de España a atacar el fuego en Portugal.

- En España: La C.A. informa al SDG de la detección y de los medios que quiere enviar. Si son necesarios medios de la DGCN, se informa al ADCIF. El SDG informa al GC portugués y autoriza la salida.

- Las autoridades en España y en Portugal informan a sus respectivas Autoridades Centrales en Madrid y Lisboa.

\section{Caso 2:}

Incendio en el país A, en zona fronteriza, cuya intensidad supera la capacidad local de A para la extinción.

- La autoridad en A solicita ayuda a la Autoridad en B para que envie medios.

- En España: El SDG informa a la C.A. para que, si es posible, envie medios de la C.A. a Portugal

- Las autoridades en España y en Portugal informan a sus respectivas Autoridades Centrales en Madrid y Lisboa.

- En España: La DGPC podrá solicitar el envío de medios de la DGCN.

\section{Caso 3:}

Incendio en el país A, fuera de la zona fronteriza, cuya intensidad supera la capacidad local de A para la extinción. 
- La autoridad central en A solicita ayuda a la Autoridad Central en B para que envíe medios.

- La autoridad Central en B envía los medios disponibles.

- En España: La DGPC podrá solicitar el envio de medios de la DGCN.

Plan de ayuda mutua para emergencias por incendios forestales en la zona fronteriza.

1. Descripción de la zona fronteriza.

- Mapas generales, mapas de modelos de combustibles, mapas forestales (en SIG si es posible).

- Informes sobre frecuencias de incendios, épocas de peligro, causas de incendios (por términos municipales).

2. Catalogo de medios de detección y extinción en las provincias fronterizas.

- Mapas de localización, disponibilidad, frecuencias de radio, números de teléfono.

- Otros recursos situados en otras provincias disponibles en caso de emergencia grave. Datos de costes.

3. Relación de Directores técnicos de extinción.

4. Autoridades competentes (Provincia, Comunidad Autónoma, Estado).

5. Procedimientos de coordinación.

6. Seguros

- Accidentes personales.

- Responsabilidad civil.

7. Formularios normalizados. (Solicitud, control, etc.)

8. Plan de ejercicios conjuntos antes de la época de peligro.

9. Informes al final de la época de peligro.

\section{Documentación para consulta}

- Legal Frameworks for Forest Fire Management: International Agreements and National Legislation, FAO, Roma 2000

- $\quad$ www.fao.org

- $\quad$ www.fire.uni-freiburg.de/emergency/int.agree.htm 